\title{
Correction to: Evaluating organochlorine pesticide residues in the aquatic environment of the Lake Naivasha River basin using passive sampling techniques
}

\author{
Yasser Abbasi • Chris M. Mannaerts
}

Published online: 8 August 2018

(C) Springer Nature Switzerland AG 2018

\section{Correction to: Environmental Monitoring and Assessment https://doi.org/10.1007//10661-018-6713-4}

The original version of this article contained an error. The pesticides concentrations units have to be updated to $\mathrm{ng} / \mathrm{L}$ (nanogram per liter) in the text and partly in Figure 5 (left part). It is confirmed that the overall findings and conclusions of the paper do not change by the update. The updated Figure 5 is presented below.

e-mail: y.abbasi@utwente.nl

C. M. Mannaerts

e-mail: c.m.m.mannaerts@utwente.nl 


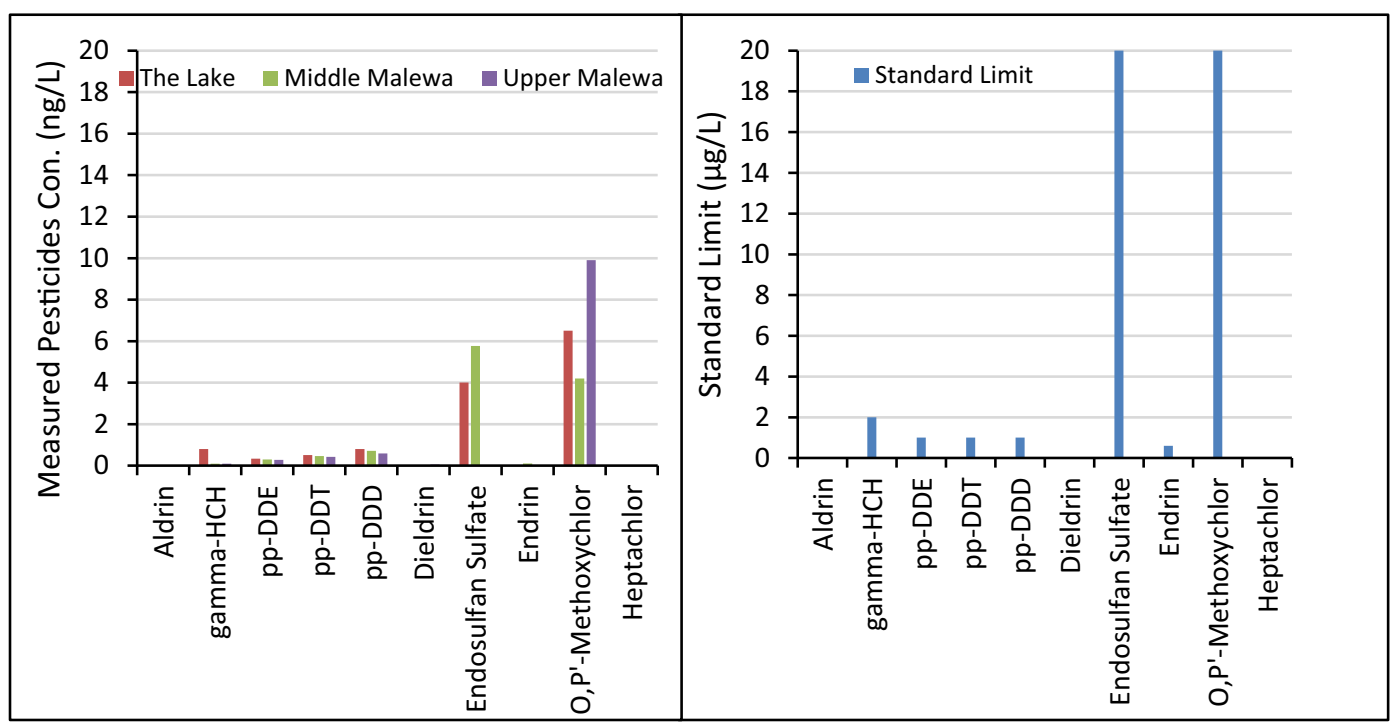

